\title{
Constructivism Teaching Mode of Intermediate for Training
}

\author{
Qin Wang ${ }^{1, a}$ and Liang $\mathrm{Ma}^{1, \mathrm{~b}}$ \\ ${ }^{1}$ Department of Surface Ship Command, Dalian Naval Academy, Dalian, 116018, China; \\ aalbert77618@163.com, bmaliang2014@tom.com
}

Keywords: Intermediate for training; Constructivism; Situational teaching

\begin{abstract}
Intermediate for training has a different from core academic education and primary teaching of distinct characteristics, the teaching is more close to the post of office and the combat needs. For intermediate training demand for teaching for teaching, as well as the intermediate for training students characteristics, this paper will research the intermediate training constructivism situational teaching model. The purpose is to improve the teaching quality of training, and strengthen the student's ability of the position.
\end{abstract}

\section{Introduction}

Innovative thinking and practical ability is the core competence of intermediate of talent training, this view is based on the modern information war demand for talent ability, and the post office demand for talent ability ${ }^{[1]}$.

Students of existing knowledge carry on the processing and evaluation, and try to understand, and through the training, innovative thinking and practical ability. To improve the traditional teaching mode, according to the characteristics of the intermediate for students, to cultivate students' ability of the two, we must build a new teaching mode.

\section{Intermediate Core Ability Training for Talents, Demand for Teaching Mode}

From the Intuition Thinking Cause Students Innovative Thinking. Bruner said, the main purpose of education is to provide students with a real-world model, students to solve all problems in life. In this mode, Bruner put forward: students are not passive knowledge receiver, but the positive information processors ${ }^{[2]}$.

For intermediate for teaching, from the perspective of system theory and information theory, every course of every professional can be divided into a series of piece of information. Students process on these segments of information through the teaching, this is an information acquisition, storage process of conversion and evaluation. From the point of view, a successful teaching has two parts: knowledge structure and teaching mode, as shown in Fig. 1. The knowledge structure is a basic concept in the field of professional disciplines, concrete embodiment is the series of information which is accepted by students, good knowledge structure makes the knowledge more easily accepted for students, these are reflected in the high quality materials, lesson plans, and a good course design and so on. Teaching mode is a system composed of students, teachers and teaching methods, etc. In this system, teachers try to through good teaching methods, and students interact, in order to make students meet for the first phase of the knowledge of cognitive, intuitive thinking. Intuitive thinking is the foundation of creative thinking training, it has special value in the process of knowledge acquisition, it got the knowledge structure involved in the field as the disciplines, so that students can practice creation. 


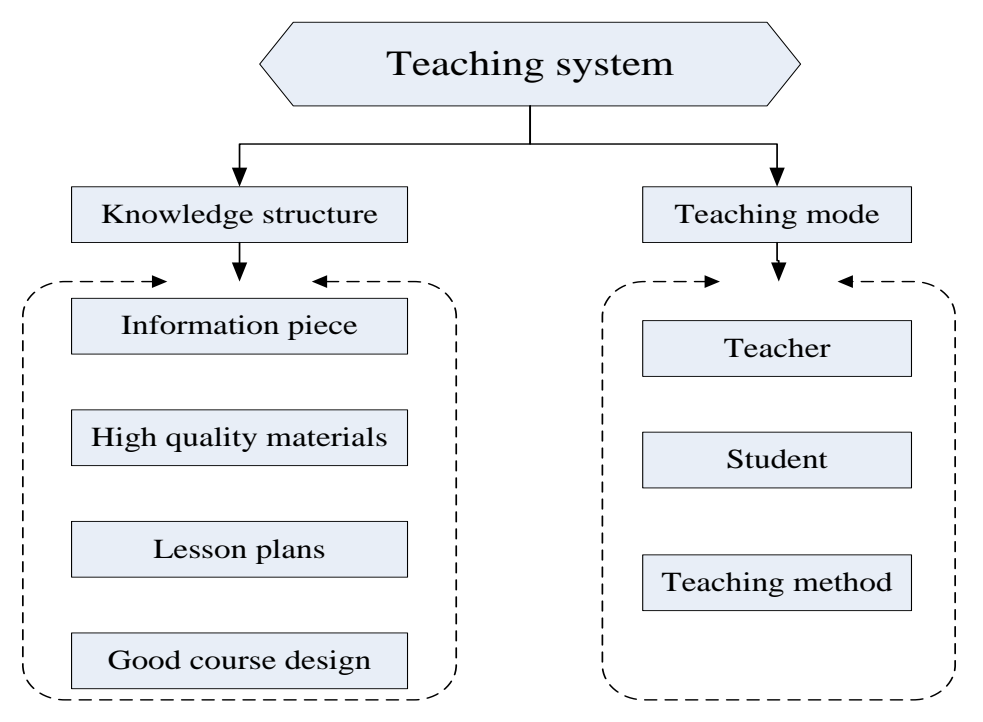

Figure 1. Step of building situation teaching mode

Creative thinking is based on the intuitive thinking, and based on the perceptual, thinking and imagining, reflected the intellectual quality of a students' comprehensive, and show the students' purpose, explore new, innovation and transcendence in the process of cognition. In the intermediate talent training scheme, we mentioned many times to cultivate talents innovation ability. Students only have a certain ability to innovate, so they can make scientific processing to create by the accumulated knowledge and experience, and then they can produce new knowledge, new ideas, new concepts, new achievements and new products. This is the modern information war of talent demand, also is the teaching needs of the combat requirement to the college.

Create a New Teaching Mode. The traditional teaching mode based on analysis and abstraction has its rationality, and will exist in the teaching of the general theory for a long time. But these patterns took the teacher as the main body. When we explore, and create a new teaching mode which took the student as the main body, the main direction is based on the body and authenticity, reflected the knowledge practice in the real world, then we can cultivate students' practice ability.

Practice ability has two meanings: one refers to the actual operation ability, the other refers to psychological potential. Actual operation ability can be trained by learning and training. Psychological potential can become a practical operation ability through learning.

Without a doubt, practice ability is the first ability of intermediate tenure position requirements. How to promote students' practice ability through teaching? Must break the traditional, and create a new teaching mode, make the students knowledge structure changing. Creating a new teaching mode, the key is to fully arouse the enthusiasm of students, and so can make independent participation and cooperation between students.

\section{The Constructivism Teaching View Based on Advanced Learning Phase}

If the study is divided into two stages, primary stage and advanced stage. The primary stage of learning is to master some important concepts and main characteristics, focus on the overall principles of learning. The primary stage of teaching generally is from simple to complex, from low to high, from local to the whole.

In advanced learning phase, more students tend to do their own thinking and ability structure based on the knowledge structure. As intermediate for students, Teaching and learning obviously can't be a primary stage, they are generally undergraduate, and have 5 to 7 years work experience, some still are master or doctor. Such a group, for their own professional field, they have mastered higher degree of knowledge structure, and have strong ability of and abstraction, and have the strong sense of self learning. So the intermediate students' learning is in the senior stage. For teaching such a group, we must seek advanced teaching concept for learning stage. 
Constructivism thought is from the theory of cognitive processing. For the students, constructivism emphasizes the initiative of learning, sociality and situational. Due to the significance of things is not completely independent of us, but from our construction, construction is everyone in their own way to understand certain aspects of things. Therefore, teaching should promote the cooperation between the students, make the students see the different point of view with him. So we often said, cooperative learning is an important way of advanced learning phase.

Teaching students for advanced learning stage, constructivism theory is put forward. Teaching cannot ignore the learner's knowledge and experience, and simply tough on learners from external knowledge, so should take the original knowledge of learners as a new growing point of knowledge, and guide the students from the original or already acquired knowledge to grow a new innovative thinking and cultivate their practice ability. The faculty is not a knowledge of the present, and should pay more attention to students understanding of various phenomena, listen to their views, think about the origin of their ideas, and according to these, guide the students to enrich and adjust their understanding. Teaching should be centered on students, teachers as the leading factor. Teachers should become a student of senior partners, to help students carry on the processing, to design good knowledge structure and build a new teaching mode, to promote students met in and based on the cultivation of innovative thinking and practical ability. At the same time, faculty will monitor student's learning process, encourage students to develop in the direction of active. Constructivism teaching concept is as shown in Fig. 2.

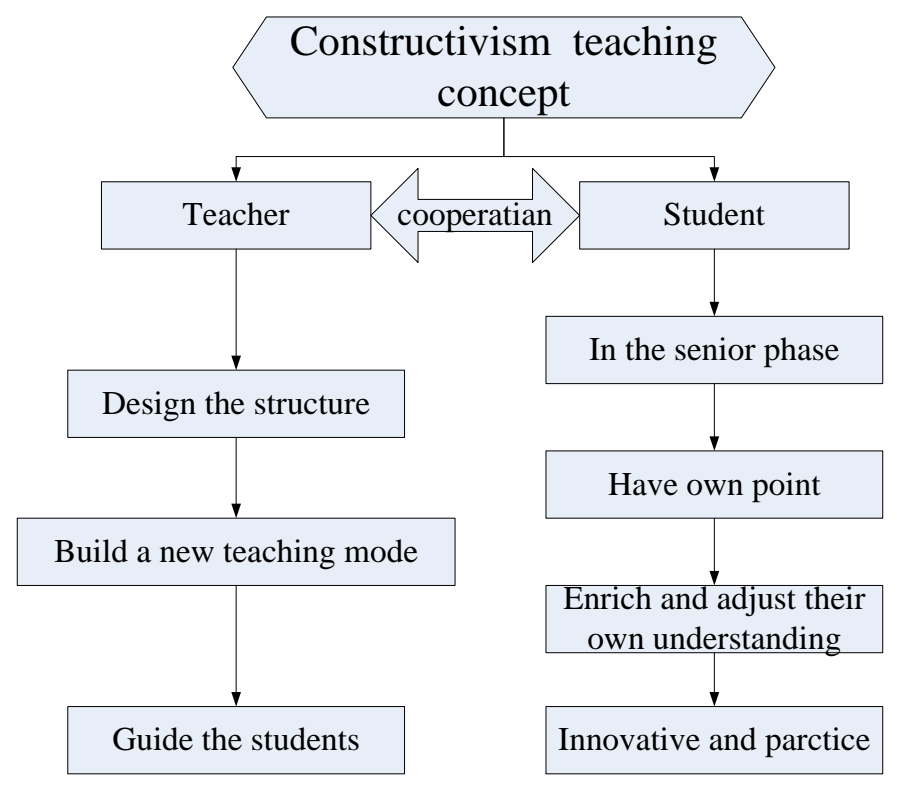

Figure 2. Constructivism teaching concept

\section{Constructivism Situational Teaching Mode of Intermediate for Training}

In the teaching process, constructivism situational teaching mode means that the teachers have a purpose to create a certain scene, in this scenario, the teacher and students get a high degree of cooperation at knowledge structure, innovation practice ability training, etc. In order to help students fully understand and get the base of the innovation practice ability. There are three building situational teaching model of step, as shown in Fig.3. 


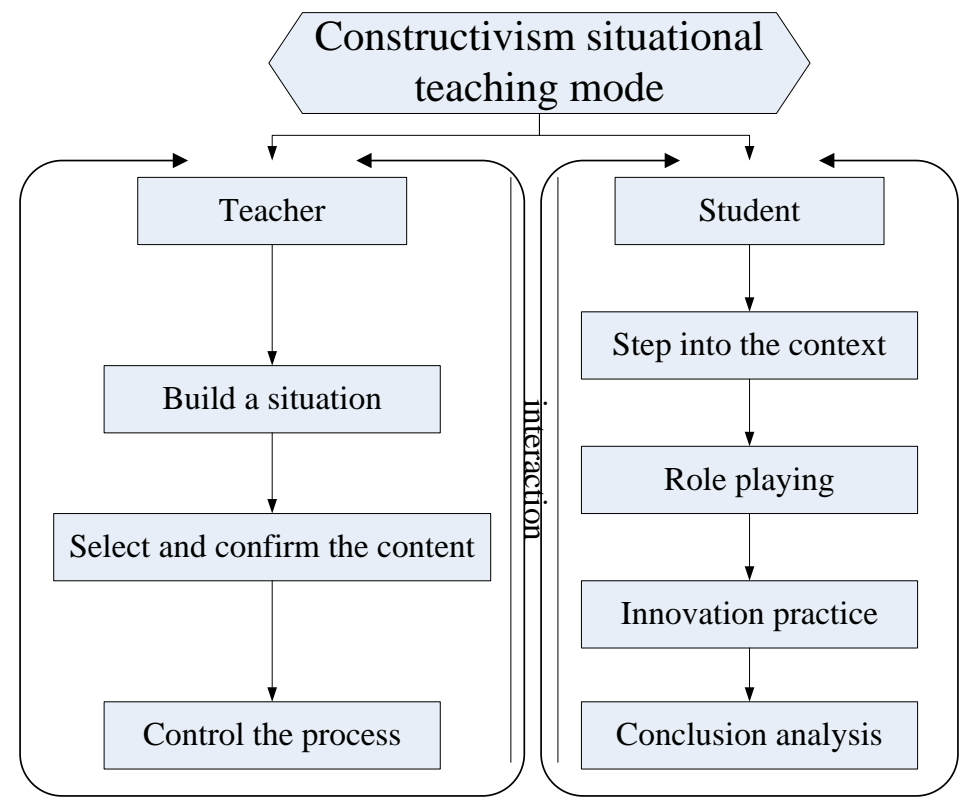

Figure3. Step of building situation teaching mode

Building a Situation. According to the intermediate course characteristics, intermediate training teaching circumstances can be divided into the context of language description, computer multimedia situation(voice, image, video), the actual equipment simulation and computer simulation. The principle of building situation is to follow.

(1)Accordance with the requirements of the teaching design. Situational construction must be based on the knowledge structure, must achieve the teaching goal.

(2)Must be sufficient analysis to the situation the main body. Situation is completed, it is necessary to faculty members and students to role play in it, such as communication, collaboration and discussion. So we must analyze the subject as the prerequisite when we build situation.

(3)The training effect and the diversity of situation. Setting up situation is not only to stimulate students' interest, must also consider the training effect of the situation. Building a situation is not to use again, and the diversity of its training should be considered. For example, the single ship command and control computer simulation situation, it can be used multiple times, not only used for training students grasp of the command process, can also used for training students' ability of emergency disposal.

(4)The oneness and richness of the situation. According to different teaching goal, we can build a single situation, such as setting the battle plan, or build rich in content, such as comprehensive exercising. The situation is only external conditions for students, students learn mainly by their intrinsic motivation.

Selection and Confirmation of Situational Content. Selection of situational content directly related to the teaching effect. There are two situation content presentation in general, examples and cases $^{[3]}$. Choosing and confirming the situation due to follow the following principles.

(1)Contents meet the requirements of the combat. The combat demand is very urgent for intermediate position, the teaching service for army talent pool, so the situation content must be close to actual combat. We can use force exercise and training to design the situation content.

(2)Situational content can't be out of the basic theory and concept of professional disciplines. All methods and techniques are derived from the basic theory and concept, knowledge structure is the basic of innovation and practice. In the teaching process, not only to teach students how to operate, the most important is teaching students how to think, all this must be based on a solid theoretical basis. So when we design the situation content, discipline of basic theories and concepts must be considered.

(3)Situational content authenticity and concreteness. The only real is validated. Even if a case must be virtual, also needs to go through real conclusion validation. Only in the detailed content of 
the real, students can have the basis to think and summarize.

Situation Process Control. Real combat is a one-off, but a combat situation can be used repeatedly, so we can study all aspects of the operation. So we can control the progress of the situation.

(1)Situation progress control with the teacher as dominant. When the teachers control the situation progress, if they use more discipline concept and theory, then they must be in a dominant position. A faculty member can control the following link: leading the students into context, role playing, innovation practice and conclusion analysis. The basis of control is following: students' reaction and performance in the situation, students' training and the creation of works, and so on. The principle of control is to guarantee into the program smoothy.

(2)Situation progress control with the teacher as dominant. When using a scene involving forces, students can be in a dominant position. Such a case, the role of faculty is the referee, and is responsible for the coordination and judgment in the process, and can terminate the process according to actual situation. After communicate with students, they can restart the process.

\section{Conclusion}

On the combat needs of the intermediate training and the students' characteristics, requires that we must explore the teaching model of good in the teaching process. The situational teaching model of constructivism is suitable for the current intermediate training teaching, and has an irreplaceable role to improve the teaching effect, to train students' ability of innovation practice, to implement the teaching purpose.

\section{References}

[1] Dalian Naval Academy, the talent training scheme. 2012. (In Chinese)

[2] Yichang Wu: The phenomenology of case teaching mode is too thin. Journal of XuZhou normal university, No.5, 2005. (In Chinese)

[3] Xiaofeng Hu: Vitual case teaching - the military teaching approach of information age. Journal of Equipment Command Technical College. No.5, 2005. (In Chinese) 